\title{
Seroprevalence Pattern in Blood Bank: Further Consideration
}

\author{
Somsri Wiwanitkit • Viroj Wiwanitkit
}

Received: 15 June 2011 / Accepted: 26 September 2011/Published online: 8 October 2011

(c) Indian Society of Haematology \& Transfusion Medicine 2011

The paper on " 5 year study seroprevalence and trends in transfusion transmitted infections among blood donors in a University Hospital Blood Bank" is very interesting [1]. Pallavi et al. concluded that "With the implementation of strict donor criteria and use of sensitive screening tests, it may be possible to reduce the incidence of TTI in the Indian scenario [1]." It is no doubt that the occulted blood pathogen can be identified in any blood banks. I agree that there should be something for corresponding to the problem. I wonder whether this can be derived by implementation of strict donor criteria. Indeed, despite the present well designed criteria, the ability of the tool for screening is not too high. The sensitive screening tests might be more rational. However, it should be kept in mind that there are many new emerging blood borne pathogens such as hepatitis $\mathrm{G}$ virus and hepatitis TT virus that might not be included in the screening program. Indeed, the solution should be more coverage and highly sensitive screening tool for determination of any problematic pathogens in donated blood.

\section{Reference}

1. Pallavi P, Ganesh CK, Jayashree K, Manjunath GV (2011) Seroprevalence and trends in transfusion transmitted infections among blood donors in a university hospital blood bank: a 5 year study. Indian J Hematol Blood Transfus 27:1-6. doi:10.1007/ s12288-010-0047-X

S. Wiwanitkit $(\square) \cdot$ V. Wiwanitkit

Wiwanitkit House, Bangkhae, Bangkok 10160, Thailand

e-mail: somsriwiwan@hotmail.com 